\title{
DETERMINANAÇÃO DO PERIGO DE INUNDAÇÃO A PARTIR DO MAPEAMENTO GEOMORFOLÓGICO DE DETALHE
}

\author{
Jairo Valdati ${ }^{1}$ \\ Daner Rosskamp Ferreira² \\ Maria Carolina Villaça Gomes ${ }^{3}$
}

Resumo: Este trabalho tem por objetivo determinar as áreas sucetíveis às inundações com base em mapeamento geomorfológico em escala de detalhe de uma área sujeita aos diferentes tipos de inundações na planície aluvial de uma bacia hidrográfica com sistema de canais entrelaçados. A área em estudo faz parte da bacia hidrográfica do Rio da Pedra, situada no extremo sul do Estado de Santa Catarina, no município de Jacinto Machado. Para o mapeamento das áreas sujeitas à inundação partiu-se da elaboração do mapeamento geomorfológico de detalhe, elaborado a partir de fotointerpretação e levantamentos de campo. Com base no mapeamento geomorfológico de detalhe, foi confeccionado o mapa das áreas de suscetibilidade à inundação, em escala de detalhe: 1: 25.000. Foram identificados e mapeados 4 níveis de perigo de inundação na planície aluvial do Rio da Pedra: perigo muito alto, alto1, alto 2, médio e sem perigo de inundação.

Palavras-chave: Perigo de inundação. Mapeamento geomorfológico. Jacinto Machado - SC.

\section{DETERMINATION OF FLOOD HAZARD FROM DETAILED GEOMORPHOLOGICAL DETTAIL MAPPING}

Abstract: This work aims to determine flood-prone areas based on detailed geomorphological mapping. This work presents the detailed geomorphological map of an area prone to different types of floods in the alluvial plain of a drainage basin with braided channels. The study area is part of the Rio da Pedra basin, located in the extreme south of Santa Catarina State, in the city of Jacinto Machado. For the mapping of flood-prone areas a detailed geomorphological mapping was developed starting by photointerpretation and field surveys. Based on the geomorphological mapping, a susceptibility map to floods was elaborated in detailed scale: 1: 25,000. Four levels of flood hazard were identified and mapped on the Rio de Pedra alluvial plain: very high, high1, high2, medium and no danger of flood hazard.

Keywords: Flood hazard. Geomorphological mapping. Jacinto Machado - SC.

\section{DETERMINACIÓN DEL PELIGRO DE INUNDACIÓN A PARTIR DEL MAPEO GEOMORFOLÓGICO DETALLADO}

Resumen: Este trabajo tiene como objetivo determinar las áreas propensas a inundaciones en base al mapeo geomorfológico a escala detallada de un área sujeta a diferentes tipos de inundación en la llanura aluvial de una cuenca hidrográfica con sistema de canales entrelazados. El área de estudio es parte de la cuenca del Rio

\footnotetext{
${ }^{1}$ Universidade do Estado de Santa Catarina (UDESC), Departamento de Geografia, Florianópolis, Brasil, jairo.valdati@udesc.br, https://orcid.org/0000-0002-7559-5315

2 Universidade do Estado de Santa Catarina (UDESC), Departamento de Geografia, Florianópolis, Brasil, danerrosskamp@gmail.com, https://orcid.org/0000-0002-0176-1763

${ }^{3}$ Universidade do Estado de Santa Catarina (UDESC), Departamento de Geografia, Florianópolis, Brasil, mcarolvg@yahoo.com.br, https://orcid.org/0000-0002-7892-0240
} 
da Pedra, ubicada en el extremo sur del estado de Santa Catarina, en el municipio de Jacinto Machado. El mapeo de áreas sujetas a inundaciones se basó en la elaboración de un mapeo geomorfológico detallado, elaborado a partir de fotointerpretación y estudios de campo. Con base en el mapeo geomorfológico detallado, se realizó el mapa de áreas de susceptibilidad a inundaciones, en escala detallada: 1: 25,000. Se identificaron y mapearon cuatro niveles de peligro de inundación en la llanura aluvial de Rio da Pedra: peligro muy alto, alto 1, alto 2, medio y sin peligro de inundación.

Palabras clave: Peligro de inundación. Mapeo geomorfológico. Jacinto Machado SC.

\section{Introdução}

O Estado de Santa Catarina é constantemente atingido por eventos naturais extremos, principalmente por chuvas de grande intensidade que deixam extensas áreas sob ameaça de inundação. No Extremo Sul Catarinense, em especial nas áreas próximas às escarpas da borda do Planalto Sul Brasileiro (Serra Geral), este tipo de evento é comumente registrado, sendo que a maior ocupação do solo se encontra nos setores dos fundos de vale que são suscetíveis a tais fenômenos.

Com relação à ocorrência deste tipo de fenômeno em território nacional, o "Atlas Brasileiro de Desastres Naturais", que congrega dados registrados entre os anos de 1991 e 2010, indica que inundações graduais ou bruscas representam cerca de $40 \%$ dos desastres registrados no Brasil. Da totalidade destes registros no território nacional, 56\% estão localizados na região Sul do país.

Um destes episódios ocorreu no final do mês de dezembro de 1995. O sul do Estado de Santa Catarina foi atingido por enxurrada nos fundos dos vales encaixados e inundações catastróficas nas planícies, associadas a precipitações elevadas e concentradas nas escarpas da "Serra Geral". Estas desencadearam processos erosivos generalizados nas escarpas e nas áreas de maior declividade situadas próximas à borda do planalto.

Os vales dos rios São Bento, em Siderópolis, dos rios Figueira e Fortuna, em Timbé do Sul, e do rio Pinheirinho, em Jacinto Machado, foram parcialmente destruídos, vitimando fatalmente 29 pessoas e deixando centenas de desabrigados. Solos agrícolas sofreram erosão e foram soterrados por seixos e troncos. De acordo com Hermann (1998), a gênese meteorológica deste episódio esteve associada à passagem de um sistema frontal, que se tornou mais intenso pela presença de um vórtice ciclônico no Rio Grande do Sul.

Apesar da magnitude do desastre e de não se ter registro histórico de ocorrências semelhantes nestes mesmos vales, este tipo de fenômeno já foi 
registrado nas encostas da "Serra Geral". Pellerin et al. (1997), em avaliação preliminar da extensão da catástrofe de 1995, observaram que a violência do fenômeno não pode ser considerada excepcional, pois toda a bacia do Rio Tubarão e do Rio Mampituba foram ainda mais atingidas em 1974. Naquele ano, nos municípios de Lauro Müller e Praia Grande os paredões da Serra Geral e as cabeceiras das duas bacias sofreram processos intensos de erosão de forma semelhante à ocorrida em Jacinto Machado, Timbé do Sul e Siderópolis em 1995.

Em relação ao evento de 1974, em Tubarão, Bigarella et al. (1975) e Suguio e Bigarella (1990) descreveram seu caráter catastrófico e o associaram às precipitações elevadas durante o mês de março em todo o sul do Estado de Santa Catarina.

A recorrência destes fenômenos na região, na escala do tempo geológico, foi reconhecida por Duarte (1995), a partir do reconhecimento de sucessivos depósitos sob a forma de leques aluviais no sopé das encostas da Serra Geral, nas bacias dos rios Amola Faca e Rocinha, em Timbé do Sul.

Estudos realizados por Pellerin et al. (1996a), nos vales dos rios Pinheirinho, Figueira e Fortuna, após o evento de dezembro de 1995, possibilitaram a subdivisão da área atingida em três zonas distintas: (i) Zona de deslizamentos generalizados nas escarpas da borda do Planalto Sul Brasileiro e cabeceiras dos rios, zona fornecedora de material; (ii) zona caracterizada pela passagem do debris flow gerado na primeira zona, ocasionando deposição de blocos nos canais fluviais; e (iii) zona de deposição de seixos e troncos, com mudanças nos canais fluviais, sendo a zona mais atingida, com destruição de casas e ocorrências de vítimas fatais.

Baseando-se nas áreas atingidas pela inundação de dezembro de 1995, Pellerin et al. (1996b) elaboraram um esboço preliminar das áreas sujeitas a inundações para a bacia do Rio Rocinha, no município de Timbé do Sul. Neste trabalho, foram identificados três setores de riscos potenciais: (i) área de divagação permanente do rio (risco permanente), (ii) leito maior do rio (risco em caso de grandes enchentes); e (iii) áreas ligeiramente elevadas na planície (risco em caso de inundação excepcional).

Os registros deixados na planície fluvial sob a forma de depósitos e morfologias podem, então, fornecer informações cruciais para a determinação de áreas de perigo de inundação. Nesse sentido, sua representação em mapeamentos 
geomorfológicos de detalhe se constitui em uma base confiável de dados sobre a dinâmica hidrológica durante eventos extremos.

Os mapas Geomorfológicos, segundo Dramis \& Bisci (1998), são entendidos como o resultado do processo de representação das formas, depósitos e processos geomorfológicos. Quando realizados em escala de detalhe, os mapas ou cartas são importantes documentos de base para estudos aplicados, tal como a delimitação de áreas de inundação e de consequência o perigo a elas associado. Desta forma, o objetivo deste trabalho foi determinar níveis de perigo de inundação a partir do mapeamento geomorfológico de detalhe na bacia do Rio da Pedra (SC/RS).

\section{Área de estudo}

A bacia do Rio da Pedra está localizada no extremo Sul do Estado de Santa Catarina e Nordeste do Rio Grande do Sul. Administrativamente, a maior parte da bacia está inserida no município de Jacinto Machado, Estado de Santa Catarina. Entretanto, a porção Oeste da Bacia, onde está a nascente do rio principal e alguns tributários, encontra-se localizada no município de Cambará do Sul, Estado do Rio Grande do Sul (figura 1). O recorte espacial definido para este trabalho envolve parte da bacia do Rio da Pedra, não abrangendo sua totalidade, pois o estudo se concentra na planície de inundação e não a toda a área da bacia. 
Figura 1- Localização da área de estudo

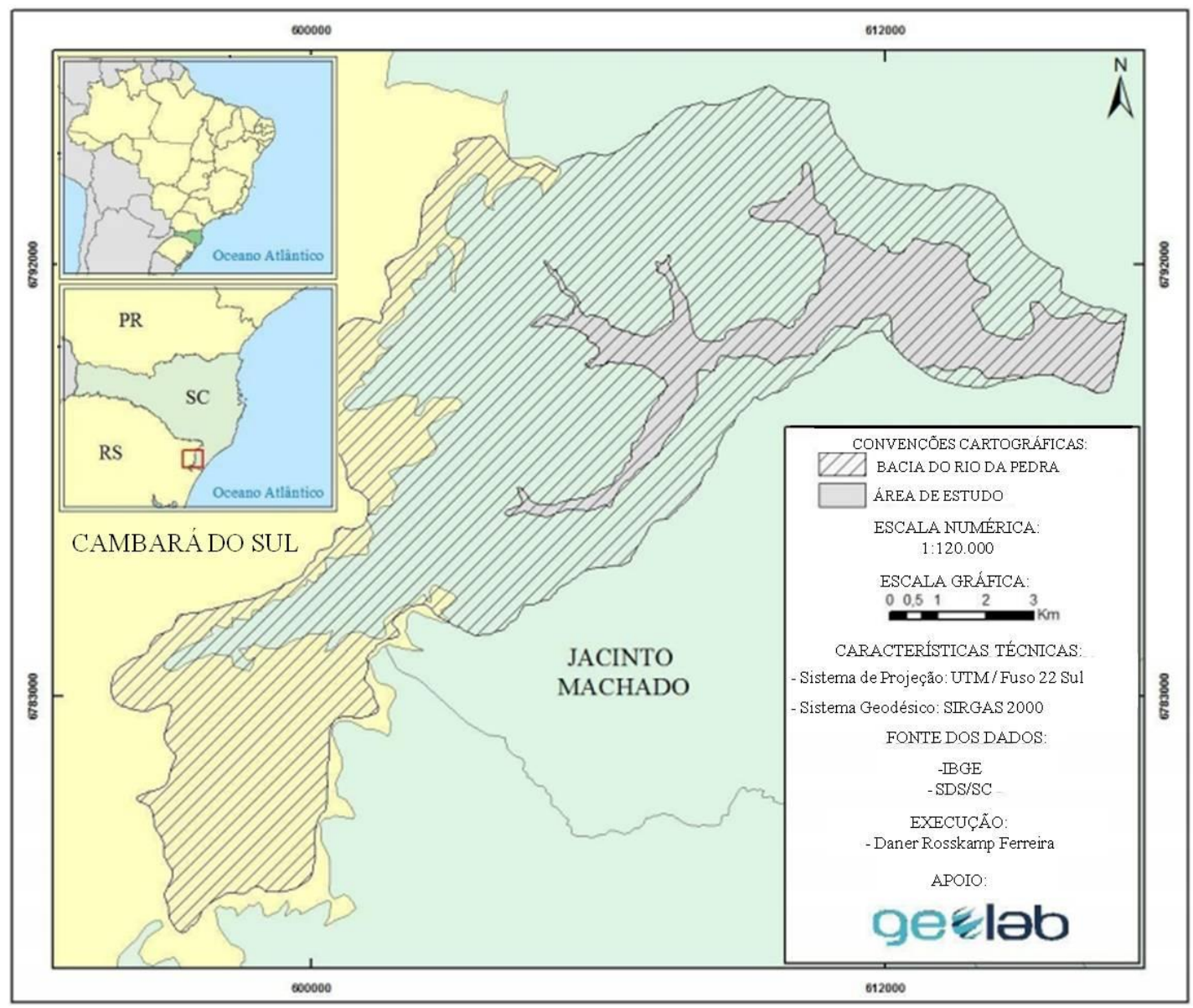

Fonte: Elaborado pelos autores, 2019.

Esta bacia é tributária do Rio Araranguá, sendo o Rio da Pedra um dos principais afluentes daquele rio. A área apresenta características muito peculiares em comparação às outras bacias de drenagem da encosta da Serra Geral, pois drena uma vasta área em suas nascentes em terrenos do planalto. Posteriormente, na planície, no médio vale, ocorre um estrangulamento da bacia, concentrando todo o fluxo de drenagem neste setor.

De acordo com os mapas geológicos de Santa Catarina (DNPM, 1986) e da Região Sul de Santa Catarina (Caruso, 1997), a área possui três unidades geológicas: Formação Serra Geral, Formação Botucatu e Sedimentos Continentais Recentes.

No que se refere aos compartimentos geomorfológicos à área pode ser dividida em quatro setores: planalto, escarpas, patamares e planície.

O Setor 01 - Planalto: compreende a porção mais a Oeste da bacia. Envolve as nascentes do rio principal e alguns de seus tributários. O substrato geológico da área dá-se pela Formação Serra Geral, caracterizado por rochas vulcânicas. 0 
relevo, por sua vez, apresenta formas planas a onduladas e baixa declividade (figura 2). A drenagem possui controle litoestrutural, seguindo geralmente as linhas de falhas e diáclases. As altitudes neste setor variam entre 900 e 1.100m.

Figura 2- Setor 01 da área de estudo, topo do Planalto Sul brasileiro

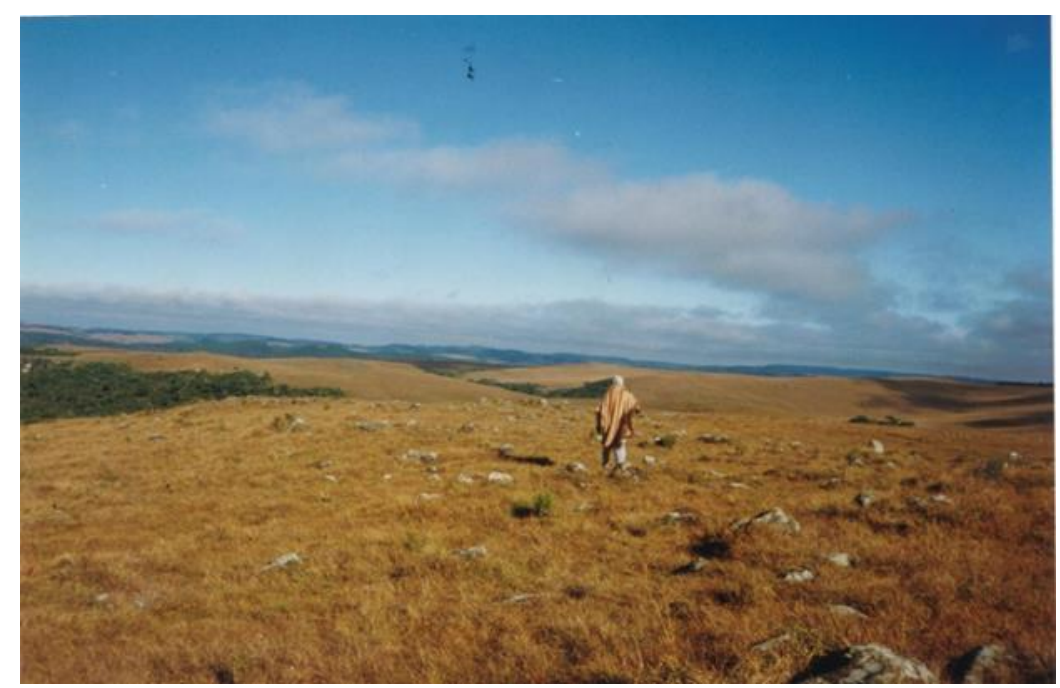

Fonte: Jairo Valdati, 2002.

O Setor 02 - Escarpas: corresponde à porção Oeste da área de estudo, envolvendo as escarpas da borda do Planalto Sul Brasileiro, conhecidas como Serra Geral, e, regionalmente, como Aparados da Serra. As altitudes neste setor variam entre 400 e $900 \mathrm{~m}$. O substrato geológico dá-se também pela Formação Serra Geral, com relevo caracterizado por formas abruptas e escarpadas, formando vales fechados, em "V", que refletem um forte controle estrutural litológico, imprimindo um padrão reto de drenagem (figura 3 ). $O$ vale principal do Rio da Pedra adentra o planalto formando um canyon, conhecido localmente como Canyon Fortaleza.

Figura 3- Setor 02 da área de estudo, escarpas da Serra Geral

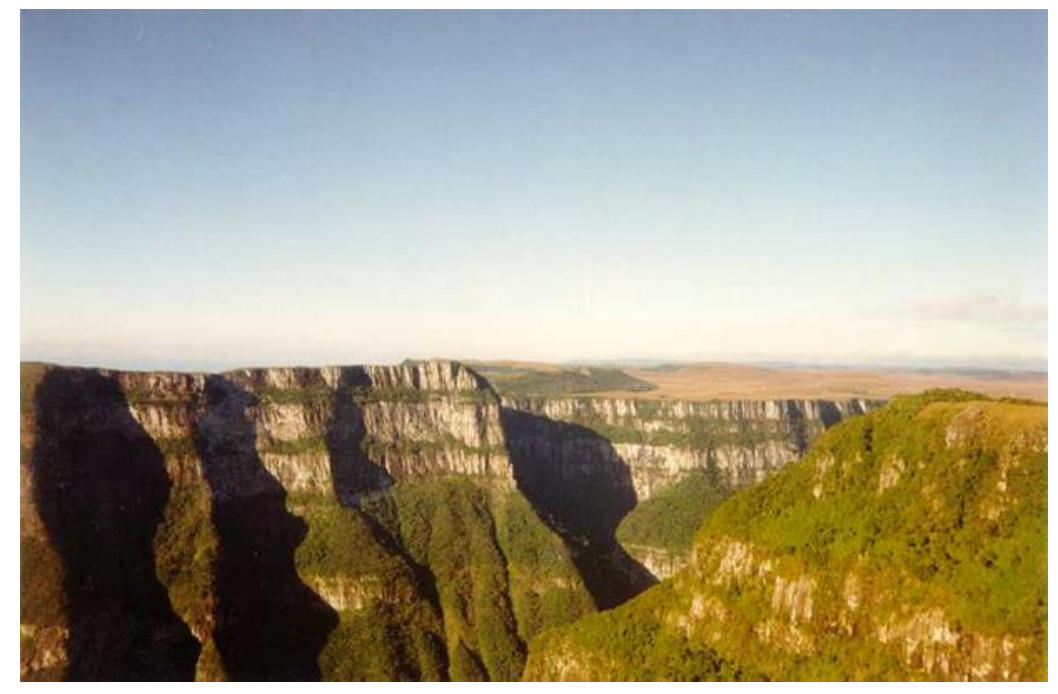

Fonte: Jairo Valdati, 2002. 
O Setor 03 - Patamares da Serra Geral: constituído geologicamente pela base da Formação Serra Geral e pela Formação Botucatu. Os arenitos da Formação Botucatu imprimem ao relevo formas colinosas, cornijas e relevo ruiniforme, que, juntamente com formas rebaixadas da Formação Serra Geral, caracterizam o terceiro setor desta bacia (figura 4). O setor é intermediário em relação ao relevo de formas abruptas e escarpadas da borda do planalto e a planície, com altitudes variando entre 400 e $200 \mathrm{~m}$.

Figura 4- Setor 03 da área de estudo, patamares da Serra Geral

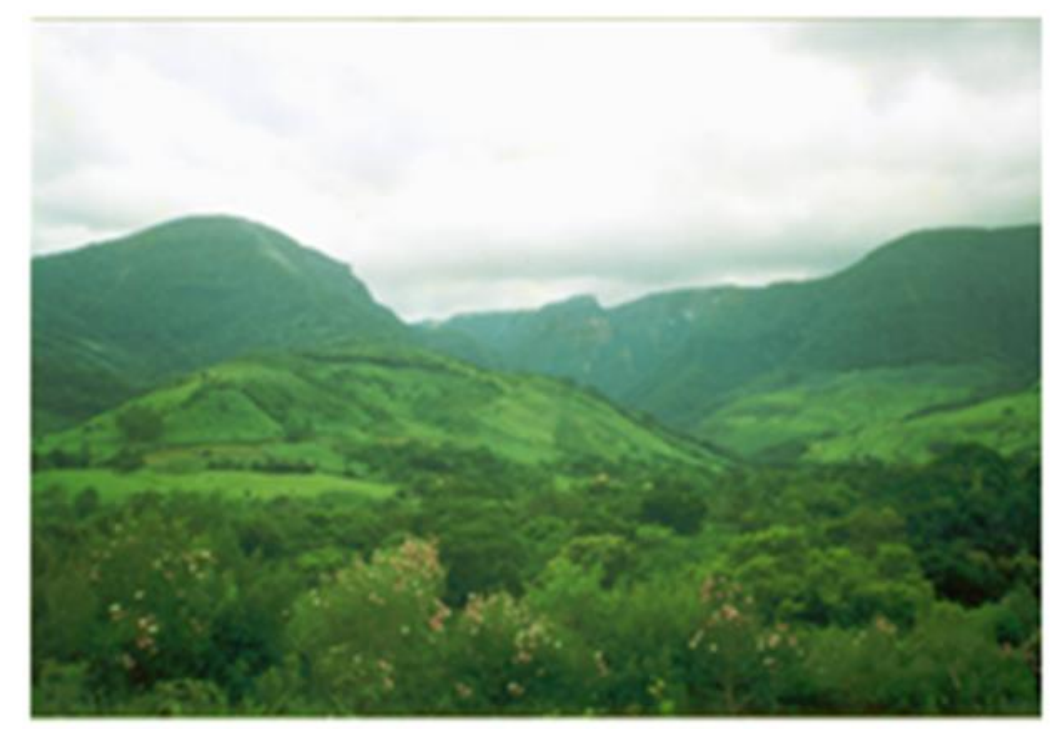

Fonte: Jairo Valdati, 2002.

O Setor 04 - Planície: é marcado por altitudes abaixo de 200m. A unidade é constituída por depósitos fluviais, com forma deposicional de leques aluviais (figura 5). O padrão de drenagem estabelecido é o entrelaçado, evidenciados por Duarte (1995). Nesta área, o Rio da Pedra corre sobre seus próprios depósitos, indicando que a área possui suscetibilidade às inundações. Devido à baixa declividade e à grande fertilidade dos solos, praticamente toda a área é ocupada para uso agrícola. Nesta unidade, concentram-se ainda o maior número de residências. 
Figura 5- Setor 04 da área de estudo, planície de inundação

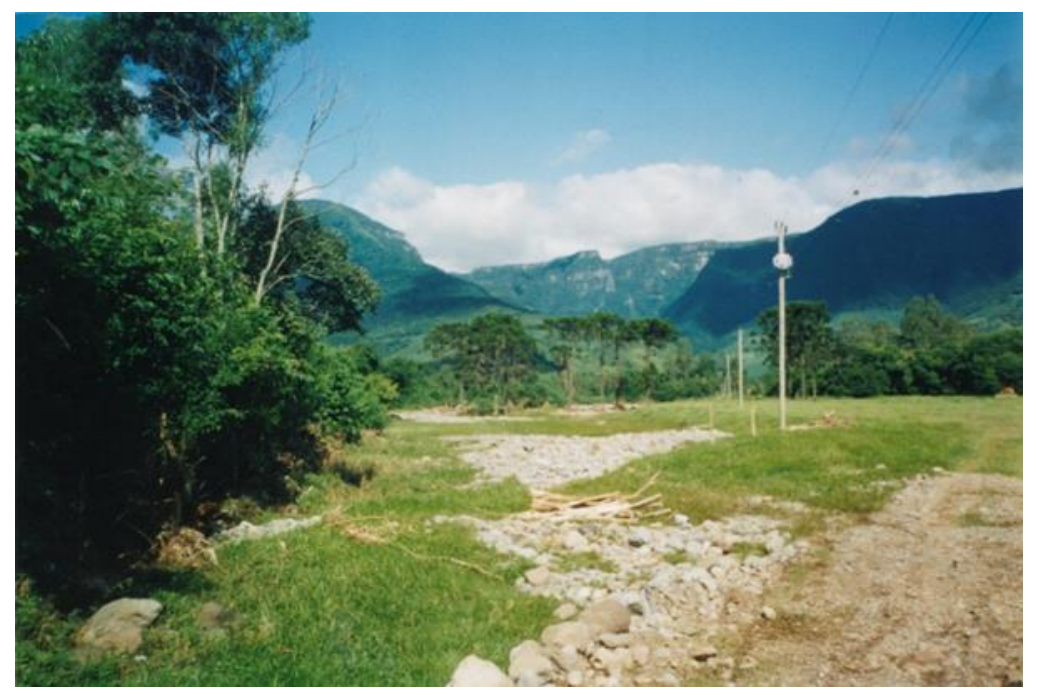

Fonte: Jairo Valdati, 2002.

A bacia do Rio da Pedra possui características fluviais muito semelhantes às áreas atingidas pelas enxurradas mencionadas anteriormente, pois a mesma abrange parte das áreas de sopé e escarpas do Planalto Sul Brasileiro, local dos eventos que anteriormente foram apontadas.

Segundo Fontanella (s.d.), de 1959 em diante ocorreram três grandes enchentes no município de Jacinto Machado, além das enchentes de 1995 e 1997: em setembro de 1959, fevereiro de 1963 e em março de 1974, com destruição de lavouras, estradas e pontes.

Anualmente, na bacia do Rio da Pedra, ocorrem cheias, e algumas vezes, inundações, como em dezembro de 1995 e em fevereiro de 1997. A inundação ocorrida no final de dezembro de 1995 no Rio da Pedra não teve as mesmas dimensões que a dos rios São Bento, Figueira, Fortuna e Pinheirinho; no entanto, houve destruição de plantações e de solos agrícolas com deposição de seixos e destruição de quilômetros de estradas e pontes. Adicionalmente, ocorreram movimentos de massa nas encostas e surgiram algumas marcas de solifluxão nas vertentes dos vales.

A área de estudo foi afetada com maior intensidade pela inundação ocorrida em 12 de fevereiro de 1997, pois as fortes chuvas, além de provocarem movimentos de massa nas encostas e mudanças nos canais fluviais, destruíram grande quantidade de plantações, pontes e estradas, chegando a inundar parte das vilas de Serra da Pedra, São Pedro e a sede do município. 


\section{Procedimentos metodológicos}

Os procedimentos adotados para este trabalho se dividem em 3 etapas: (i) mapeamento das formações geológicas; (ii) mapeamento geomorfológico de detalhe; e (iii) determinação dos níveis de perigo de inundação. Inicialmente, foi realizado um trabalho de campo para reconhecimento da área e identificação de feições gerais e operacionais da área de estudo, tais como dificuldade ou facilidade de acesso, registro fotográfico e contato com moradores locais.

O mapeamento das formações geológicas teve por objetivo detalhar as áreas de ocorrência dos depósitos fluviais, levando-se em conta a tipologia dos depósitos, tamanho, forma de deposição, imbricamento, dentre outros.

O mapeamento das feições geomorfológicas foi realizado a partir de fotointerpretação e trabalhos de campo. Para a fotointerpretação foram utilizadas fotografias aéreas pancromáticas, dos levantamentos aéreos do Estado de Santa Catarina, realizados em 1957 e 1978, ambos com escala aproximada de 1:25.000. Além das fotografias pancromáticas, foram utilizadas fotografias aéreas oblíquas do tamanho $10 \times 15 \mathrm{~cm}$, obtidas por máquinas fotográficas convencionais, além de imagem de satélite Landsat. As fotografias aéreas oblíquas serviram para auxiliar os trabalhos de campo e no levantamento de informações como o sistema viário, áreas urbanizadas e algumas feições geomorfológicas situadas na planície aluvial. As feições geomorfológicas identificadas, tanto as formas das encostas quanto as da planície, foram expressas graficamente por formas pontuais (símbolos) ou por polígonos. Não houve mapeamento detalhado de feições em vertentes e outros compartimentos pouco suscetíveis à inundação, pois tal detalhamento fugia ao escopo do trabalho.

O perigo de inundação foi identificado a partir: (i) da confecção de 7 perfis topográficos transversais ao Rio da Pedra, levando-se em conta a ruptura de declive próximo às cotas topográficas atingidas por inundações recentes nas bacias dos rios Figueira e Pinheirinho, ambas contíguas a ela; (ii) das características dos depósitos aluviais, tais como a granulometria e o grau de alteração do material; e (iii) interpretação do mapeamento geomorfológico.

Diante disso, foram definidos 4 níveis de perigo (muito alto, alto, médio e sem perigo). Quanto ao nível alto, este foi dividido em duas classes, considerando-se a dinâmica fluvial e a topografia. Há uma tênue diferença topográfica na área identificada com este nível de perigo (mais elevada à margem esquerda), que 
condiciona, portanto, os rompimentos do canal em sua margem direita (indicado pela geometria do canal).

\section{Resultados e discussão}

\section{Mapeamento das formações geológicas}

A bacia do Rio da Pedra é majoritariamente constituída dos basaltos da Formação Serra Geral (figura 6). Uma particularidade encontrada no mapeamento se refere ao afloramento de um sill, que aparece em posição topográfica abaixo dos arenitos da Formação Botucatu.

Figura 6- Formações geológicas da bacia do Rio da Pedra

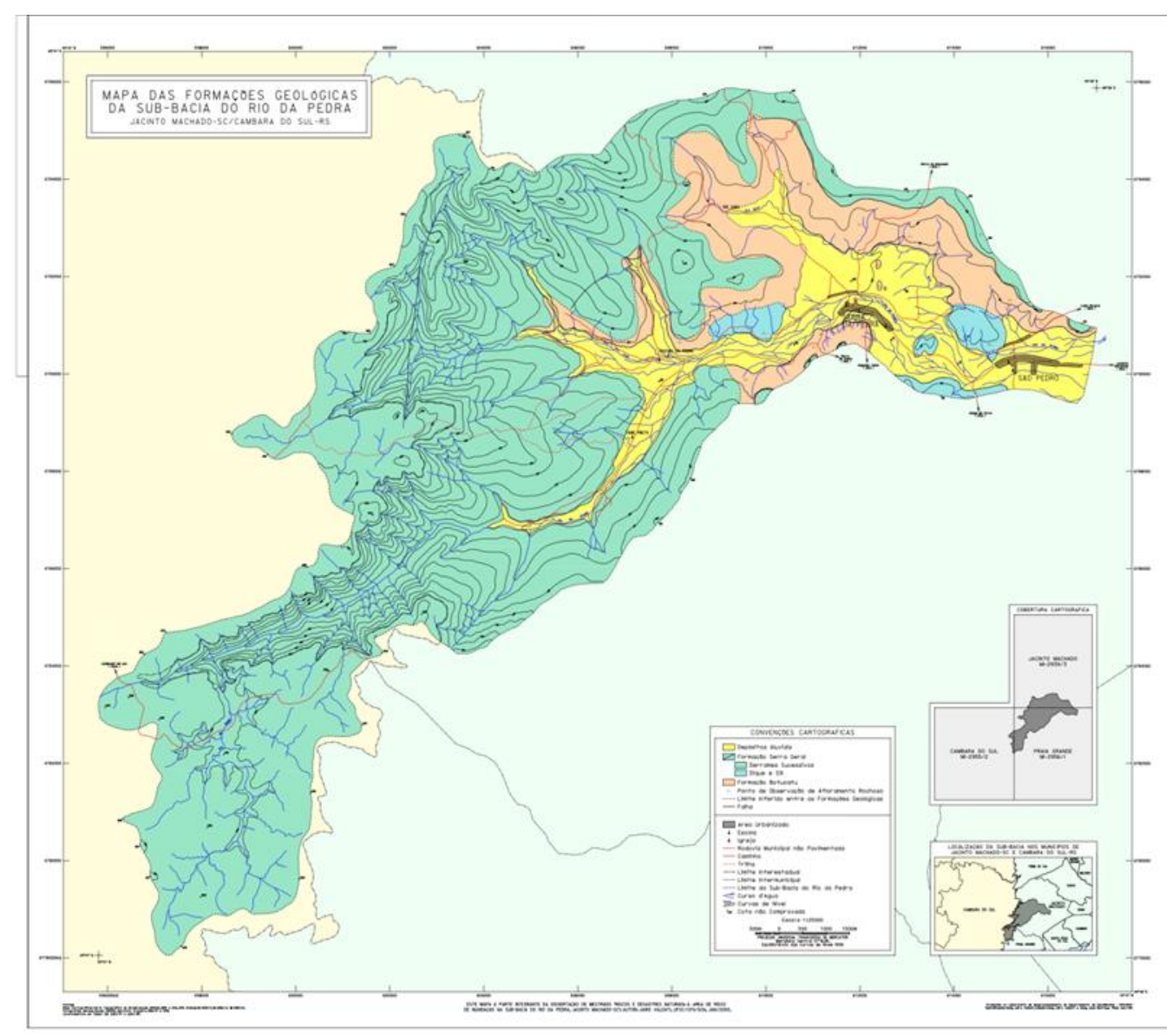

Fonte: Elaborado pelos autores, 2019

A Formação Botucatu é nitidamente representativa na porção norte da bacia, com espessa camada de afloramentos de arenitos. Os afloramentos vão diminuindo progressivamente para Oeste. Próxima à vila Costão da Pedra, à margem direita do Rio da Pedra, os arenitos desaparecem abruptamente, dando lugar a depósitos de encostas associados à Formação Serra Geral. 
Observa-se também que entre os depósitos fluviais que compõem a planície aluvial aparecem afloramentos de arenitos, os quais, devido sua pouca elevação topográfica, podem ser facilmente confundidos com depósitos fluviais.

Nota-se que o canal do Rio da Pedra apresenta-se muito sinuoso na área da planície onde ele corta os afloramentos em forma de sill. A forma como este sill está disposto sugere uma deformação anticlinal na Formação Botucatu. Observa-se ainda que ocorre um estrangulamento no vale à medida que este corta esse tipo de afloramento. Acredita-se que tanto a sinuosidade do canal quanto o estreitamento estão condicionadas à litologia da área. De um modo geral, pode-se considerar que na maior parte da planície, o Rio da Pedra possui o canal esculpido em seus próprios depósitos. Entretanto, deve-se atentar para os condicionantes litológicos que também estão presentes neste tipo de ambiente, os quais são de fundamental importância para se determinar as áreas potencialmente inundáveis.

\section{Mapeamento geomorfológico de detalhe}

O resultado do mapeamento geomorfológico da bacia do Rio da Pedra é apresentado na figura 7. Devido à escala definida para o mapeamento (1:25.000), muitas morfologias presentes na planície não puderam ser representadas, tais como as dimensões (largura) dos canais, barras fluviais e pequenos lóbulos. 
Figura 7- Principais feições geomorfológicas da bacia do Rio da Pedra

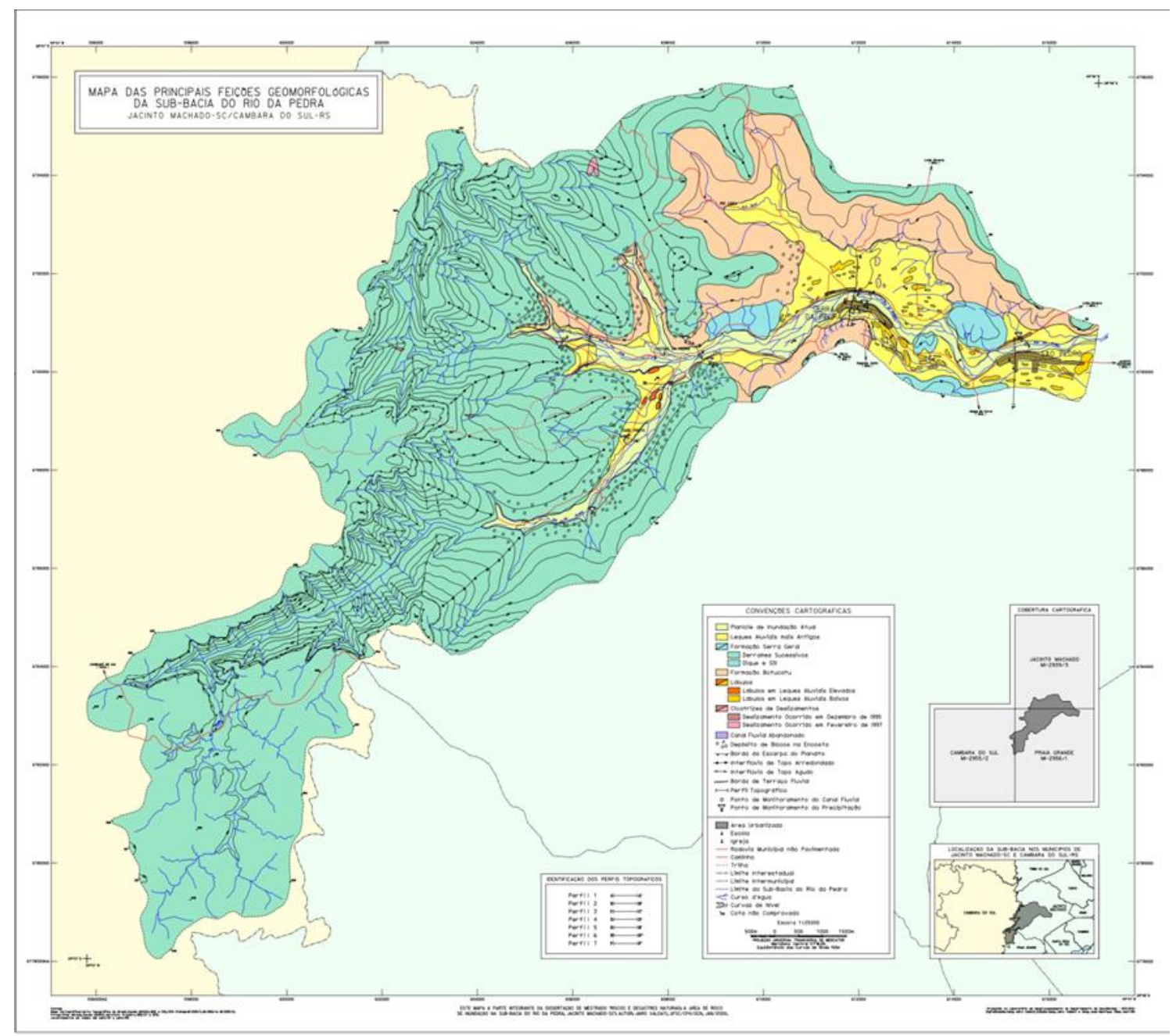

Fonte: Elaborado pelos autores, 2019.

Ademais, não houve mapeamento detalhado das morfologias das encostas e áreas pouco suscetíveis de serem inundadas (sem evidência de eventos pretéritos in locu), pois tal detalhamento foge aos propósitos deste trabalho. Portanto, é justificável a designação Mapa das Principais Feições Geomorfológicas e não simplesmente Mapa Geomorfológico. Optou-se, igualmente, por deixar como representação de fundo o tipo de Formação Geológica, o que permitiu associar diretamente as morfologias ao tipo de rocha e às suas estruturas.

\section{Morfologias mapeadas nas encostas}

- as bordas do planalto, formadas a partir da erosão fluvial sucessiva, é representada por escarpas abruptas. A borda da escarpa deste planalto indica 0 limite leste do Planalto Sul Brasileiro e, em muitos locais, funciona como divisor 
topográfico entre as bacias hidrográficas que escoam para o litoral catarinense e as que drenam o nordeste do Rio Grande do Sul;

- os interflúvios, que figuram como as partes mais elevadas dentro desta subbacia e funcionam como pequenos divisores topográficos, foram divididos em interflúvios de topo agudo e de topo arredondado. Os primeiros fazem parte da escarpa do planalto, enquanto os últimos representam os topos dos morros que se prolongam para leste. Ambos resultam da ação erosiva que produz a dissecação do planalto e representam o recuo da linha de escarpa para oeste;

- os depósitos de blocos, que aparecem no limite inferior dos afloramentos das rochas efusivas e superior dos arenitos da Formação Botucatu. Convém destacar que, embora no mapa estes blocos tenham sido representados por símbolos, eles não estão representando individualmente os blocos, mas sim a forma que está impressa no relevo. Estes blocos são de rochas efusivas (basalto) desprendidos das partes mais íngremes das encostas e com subsequente depósito nas áreas de menor declividade.

Nas encostas e borda da escarpa, foram mapeadas algumas cicatrizes de movimentos de massa, que estão representados na forma areal. As cicatrizes de movimentos de massa foram divididas em:

- movimentos de massa ocorridos em 1995: estas cicatrizes estão associadas ao evento pluviométrico de final de dezembro de 1995 que provocou os movimentos de massa generalizados nas bacias vizinhas (rios Pinheirinho, Figueira e Fortuna). Eles revelam a morfodinâmica das áreas de encostas íngremes ou escarpa do planalto;

- movimentos de massa ocorridos em 1997: esta cicatriz é resultado do processo desencadeado pelo evento pluviométrico ocorrido em fevereiro de 1997.

\section{Morfologias mapeadas na planície}

Ao contrário das morfologias anteriores, as da planície foram quase todas expressas de forma real, e estão associadas aos processos aluviais e fluviais principalmente ao de deposição de material nas planícies e nos canais. As principais unidades mapeadas foram:

- planície de inundação atual: evidencia as áreas que atualmente são inundadas quando ocorrem as inundações;

- leques aluviais: este tipo de morfologia foi mapeada como ocupando toda a planície aluvial e já haviam sido identificadas por Duarte (1995) como de depósitos 
fluviais em forma de leques. À identificação de Duarte (1995) acrescentou-se a informação de que estes depósitos apresentam cotas topográficas distintas, sendo os depósitos aluviais próximos da escarpa do planalto mais elevados que os mais à jusante.

- lóbulos: formados por depósitos fluviais, estas formas estão dispostas pela planície e compõem os leques aluviais. Subdividiu-se estas morfologias em duas classes, a saber, os lóbulos localizados nos depósitos fluviais mais elevados e os situados nos depósitos mais baixos. Os primeiros correspondem aos depósitos mais próximos às áreas-fontes e se encontram totalmente alterados. Os lóbulos situados nos leques aluviais de menor desnível, por sua vez, apresentam diversos estágios de alteração;

- canal fluvial abandonado: tipo de morfologia encontrada nas áreas de depósito fluviais próximas às escarpas. Evidenciam o resultado da dinâmica do sistema de rios entrelaçados condicionados aos leques aluviais de sopé de escarpa;

- borda do terraço fluvial: único tipo de morfologia mapeada na planície representada graficamente por símbolos que revela uma ruptura de declive de até $5 \mathrm{~m}$ entre o limite dos depósitos fluviais mais elevados e a planície de inundação atual. Ao contrário das demais, esta morfologia está associada aos processos erosivos que ocorrem nas margens da planície de inundação atual. Tais morfologias foram aqui denominadas bordas de terraço, embora os terraços ao qual estejam associadas façam parte dos depósitos em forma de leque.

Quanto às áreas de planície, observa-se que a planície de inundação atual possui limites mais definidos e de maior largura nas áreas acima da vila Serra da Pedra. A leste desta vila, a planície de inundação atual possui limites bastante suaves, dificultando a individualização da mesma. A maior largura desta parte da planície aluvial relaciona-se à presença de canais entrelaçados.

Em relação aos depósitos em forma de leques aluviais, avalia-se que aqueles próximos à vila Serra da Pedra, na margem esquerda do Rio da Pedra, representam em planta uma morfologia típica de leque, sendo este leque limitado em sua parte superior por pequenos afloramentos de arenitos Botucatu. Pode-se considerar, então, que nestas áreas existe coalescência de depósitos fluviais e que estes podem representear diferentes estágios de deposição, bem como ser individualizados como pequenos leques aluviais.

Os depósitos mais antigos situados próximos das áreas fonte de material (escarpas do planalto) estão em cota topográfica mais elevada e podem ser 
individualizados como terraços fluviais. No entanto, no local onde se localiza a comunidade de Tigre Preto, verificam-se formas lobulares sobre o mesmo e o formato como estes lóbulos estão dispostos permite associá-los aos mesmos processos geradores dos lóbulos nas planícies menos elevadas. No entanto, devese considerar que estes já sofreram ação antrópica e estão sendo retrabalhados atualmente por processo pluviais.

A gênese destas morfologias deve ser estudada com mais detalhe, levandose em conta os níveis de base local de deposição diferentes dos atuais, bem como a influência tectônica, ainda pouco conhecida nestas áreas.

À primeira vista, o estrangulamento causado pelo afloramento das rochas magmáticas que compõem o sill na planície aluvial entre as vilas Serra da Pedra e São Pedro, formam níveis diferenciados de deposição, sendo que as áreas acima deste estreitamento apresentam nível de base local de deposição mais elevado. Nota-se também, que, em caso de grandes inundações, o limite da planície atual é ultrapassado e o fluxo pode atingir áreas fora daquelas inundadas frequentemente.

Um fator a ser apreciado é a localização das áreas urbanas das vilas Serra da Pedra e São Pedro. Tais vilas, situadas no limite das planícies de inundação atual, apresentam crescimento orientado para as áreas frequentemente inundáveis, principalmente no caso da vila Serra da Pedra.

Quanto ao uso agrícola, constatou-se que, para o plantio, especialmente no cultivo de arroz irrigado, são feitos reafeiçoamentos das formas existentes na planície, o que faz com que os lóbulos que se encontravam elevados sejam aplainados, ficando a área em cota topográfica inferior àquela de origem, o que aumenta sua suscetibilidade a inundações.

\section{Mapeamento das áreas de perigo de inundação}

A partir dos critérios descritos anteriormente estabeleceu-se as áreas que podem ser atingidas por inundações na bacia do Rio da Pedra. A espacialização da possibilidade de ocorrência das inundações é o que se denomina de perigo e a hierarquia dele é o que se denomina de nível de perigo de inundação.

A partir do mapeamento geomorfológico de detalhe e do entendimento da dinâmica da bacia, assinala-se espacialmente as áreas com perigo de inundação. Nota-se que nem todas as áreas são atingidas com igual intensidade em caso de uma inundação, do mesmo modo que as inundações não possuem a mesma 
intensidade ou atingem a mesma magnitude. Assim, foram estabelecidos 4 níveis de perigo, os quais estão representados no Mapa de perigo de inundação (figura 8).

Figura 8- Áreas de perigo à inundação na planície aluvial da bacia do Rio da Pedra

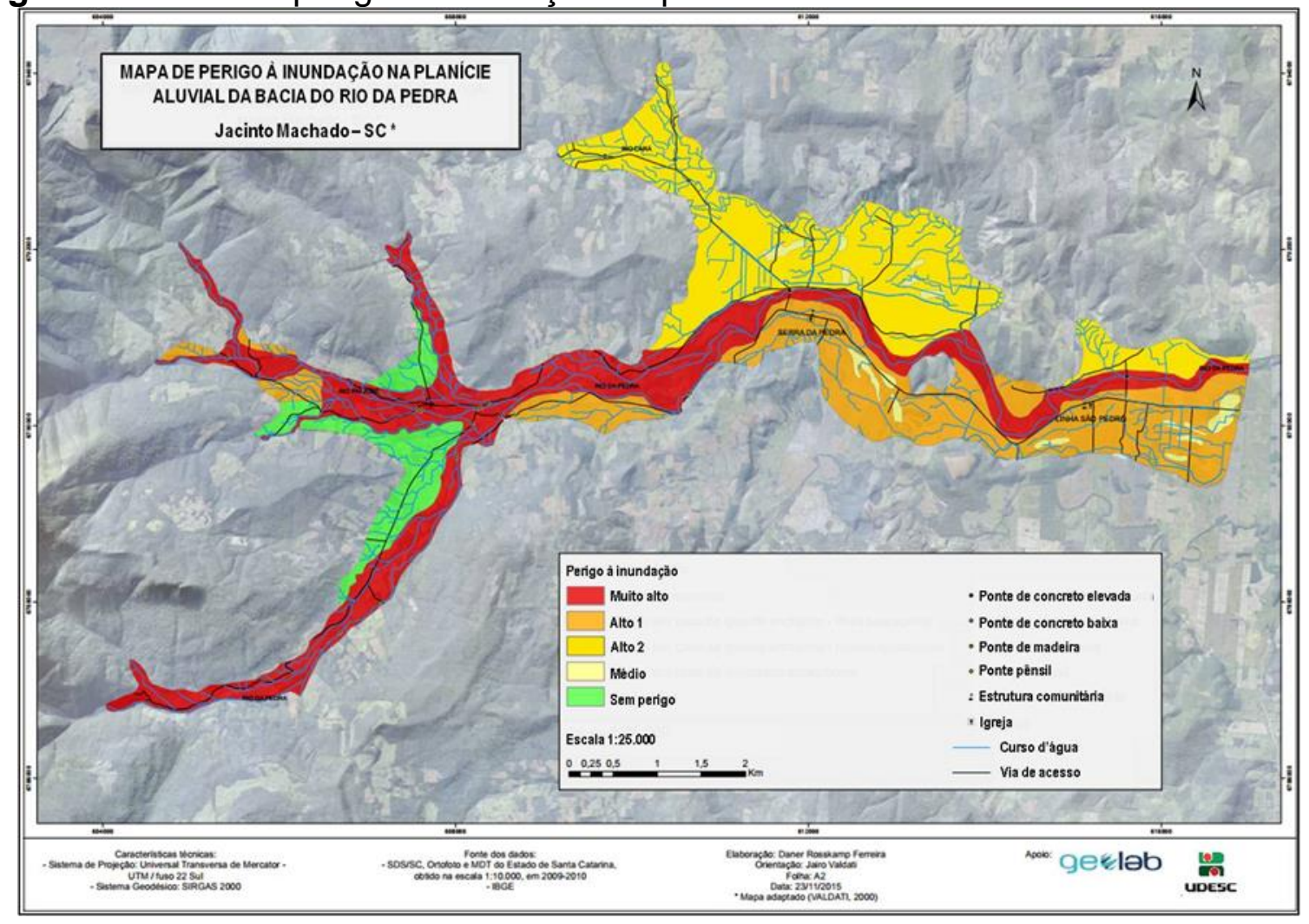

Fonte: Elaborado pelos autores, 2019

Para expressar graficamente a diferença dos níveis de perigo utilizou-se as cores com tonalidades que vão do vermelho ao verde, simbolizando, respectivamente, áreas de perigo permanente e áreas que não oferecem perigo: vermelho, laranja, laranja escuro, amarelo e verde.

As áreas em vermelho representam o primeiro nível de perigo (Nível Muito Alto), isto é, perigo permanente de inundação. Isto se deve ao fato destas áreas fazerem parte da planície de inundação atual do rio, local onde ocorrem os entrelaçamentos entre os canais fluviais. São, portanto, as áreas de maior perigo às inundações, uma vez que estão sujeitas às enchentes, inundações propriamente ditas e enxurradas.

O segundo nível (Nível Alto) foi subdividido em duas classes (Alto1 e Alto 2), representadas pelas cores laranja escuro e laranja, respectivamente. Ambas as classes retratam perigo de inundação em caso de grande enchente. 
A cor laranja escuro (Nível Alto 1) representa espacialmente as áreas mais susceptíveis de serem atingidas. O critério para se definir esta classe foram: 0 topográfico, através da realização de perfis, e pela identificação dos pontos de rompimento da margem do canal fluvial principal. A área representada em cor laranja (Nível Alto 2) indica que a possibilidade de ocorrência de inundação em caso de cheia é menor, pois as extensões em laranja estão topograficamente mais elevadas que as áreas da classe anterior. Além de possuírem limite bem definido (através da borda de terraço) em comparação às áreas do primeiro nível de perigo.

O terceiro nível de perigo (Nível Médio) está expresso no mapa pela cor amarela. Este grau está associado à morfologia de lóbulos que, topograficamente, são as formas mais elevadas na planície. Estas áreas representam perigo de inundação em caso de enxurradas excepcionais, geralmente associadas a fluxos de lama e de detritos nas áreas de maior declividade.

Esses tipos de fluxos podem atingir o topo dos lóbulos, principalmente os de cota topográfica menos elevada, situados próximos aos pontos de rompimento do canal ou na direção do fluxo nestes locais. Além das morfologias originadas por depósitos fluviais, colocamos neste grau de perigo as pequenas áreas de afloramentos de arenito Botucatu que se encontram situadas na planície, uma vez que estão topograficamente pouco elevadas.

A cor verde representa o quarto nível (Sem Perigo), ou seja, as áreas que não oferecem perigo de inundação, correspondendo aos depósitos fluviais que se encontram em cotas topográficas relativas acima dos $15 \mathrm{~m}$, na maior parte dos casos, 20 metros. Este grau está associado aos depósitos fluviais que apresentam estágio de alteração muito evoluído, uma evidência disto é o fato de que a maioria dos clastos se encontra completamente alterados. Deste modo, a posição topográfica associada ao estágio de alteração demonstra que estas áreas não estão mais inseridas na dinâmica atual dos leques aluviais do sistema fluvial do Rio da Pedra.

Estes níveis de perigo de inundação representam uma situação hipotética, uma vez que foram estabelecidos a partir da identificação de registros de eventos pretéritos observados em campo. Portanto, fenômenos de maior magnitude podem ocorrer, vindo atingir locais não mapeados como áreas de perigo de inundação. Outrossim, alerta-se que os limites das áreas de diferentes graus de perigo não são tão abruptos, pois muitas vezes a transição entre uma área e outra é bastante suave. 
Quanto à possibilidade de ocupação das áreas classificadas com algum grau de perigo à inundação, sugere-se que os terrenos de perigo muito alto não sejam destinados à ocupação residencial ou outras benfeitorias, pois trata-se de locais que podem ser inundados frequentemente.

As áreas de perigo Alto 1 e 2 necessitam de estudos pontuais sobre sua ocupação residencial. Essas podem ser atingidas em caso de ocorrência de inundações excepcionais, caracterizadas por fluxos de lama e de detritos. Chama-se a atenção para as áreas urbanas das vilas Serra da Pedra e São Pedro, que se situam nas áreas identificadas como pertencentes a este grau de perigo.

O perigo de Nível Médio, estabelecido em áreas da planície aluvial que oferecem menor perigo de inundação, e que são, portanto, as mais indicadas para uso residencial e outras benfeitorias. Contudo, alerta-se que estas áreas também podem ser atingidas por enxurradas excepcionais, mas que não possuem registro histórico neste local e em áreas contíguas a esta bacia.

\section{Considerações finais}

Este trabalho teve por objetivo aplicar o mapeamento geomorfológico de detalhe para a previsão de áreas com perigo de inundação. Para tanto, buscou-se identificar as feições morfológicas típicas de ambiente fluvial e caracterizar os materiais que as constituem, e que permitiram a definição de quatro níveis de perigo na bacia do Rio da Pedra, em Jacinto Machado - SC.

A distribuição espacial dos níveis estabelecidos foi fortemente influenciada pelas feições registradas a partir de trabalhos de campo. Desta forma, acredita-se que parâmetros morfométricos, como a topografia, há muito tempo utilizadas como base para delimitação de áreas sujeitas à inundação, não oferecem elementos suficientes para a compreensão da dinâmica fluvial, sobretudo em sistemas de canais entrelaçados típicos de depósitos proximais de leques aluviais, como a bacia do Rio da Pedra.

Os níveis de perigo de inundação foram estabelecidos considerando-se os processos naturais que ocorrem na sub-bacia do Rio da Pedra. Contudo, a ocupação destas áreas pode modificar pontualmente a dinâmica destes processos, criando ou acentuando outros níveis de perigo de inundação.

Sugere-se que nos mapas geomorfológicos estejam inseridos dados hidrográficos, litológicos e hipsométricos, pois essas informações vistas em conjunto permitem compreender melhor o dinamismo ambiental da área mapeada. Com isso, 
tem-se elementos que permitem estabelecer relações entre os processos de erosão, transporte e deposição que ocorrem na área e identificar seus principais condicionantes.

Recomenda-se, ademais, estudos em maior escala - principalmente nas áreas onde se verifica crescimento urbano - e que se proceda um levantamento topográfico minucioso nestas áreas, para se alcançar maior detalhamento na delimitação das áreas de perigo vinculado às inundações. Por fim, é lícito ressaltar que, embora o mapa de perigo de inundação sirva como um alerta, o mesmo não deve ser usado como instrumento definitivo para tomada de decisões.

Os avanços recentes na área das Geotecnologias, como o uso dos VANT's para levantamentos de superfície vem colaborando para análises em escala de detalhe. No entanto, para determinação de áreas suscetíveis à inundação, não se deve ater-se somente à topografia, mas ao entendimento da forma por ela representada, seja de uma dinâmica atual ou passada, ressaltando a importância da representação geomorfológica através do mapeamento de detalhe com base nos processos geomorfológicos.

\section{Agradecimentos}

Este trabalho é fruto de alguns anos de estudos e muitas idas a campo, com a orientação do professor Joel Pellerin. Um grande mestre, que calmamente nos ensinou que é necessário entender a dinâmica da paisagem para poder representála. Um agradecimento especial a este mestre/amigo.

\section{Referências bibliográficas}

BIGARELLA, J. J, Catastrophic events in the Tubarão area. In: Boletim Paranaense de Geociências. № 33, 1975. p. 200-206.

CARUSO JR., F. Mapa geológico e de recursos minerais do sudeste de Santa Catarina. Florianópolis: DNPM/UFRGS-CECO, 1995. Mapa color. 95 × $60 \mathrm{~cm}$. Escala $1: 100.000$.

DNPM - DEPARTAMENTO NACIONAL DA PRODUÇÃO MINERAL, 1986. Mapa geológico do Estado de Santa Catarina. Florianópolis: DNPM, 1986. Escala 1:500.000. DRAMIS, F., BISCI, C. (1998) - Cartografia Geomorfologica: manuale di introduzione al rilevamento ed alla rappresentazione degli aspetti fisici del territorio. Pitagora Ed., Bologna. 215p.

DUARTE, Gerusa Maria. Depósitos Cenozóicos Costeiros e a Morfologia do Extremo Sul de Santa Catarina. 1995. 351 f. Tese (Doutorado) - Curso de Geologia Sedimentar, Instituto de Geociências, Universidade de São Paulo, São Paulo, 1995. 351p. 
FONTANELLA, Pe. Herval. Jacinto Machado: capital da banana. Tubarão-SC: Dehon Ltda. 90p. (s.d.).

HERRMANN, M. L. Problemas ambientais na faixa central do litoral catarinense. São Paulo, USP, Instituto de Geociências, 1998. 307p. Tese de Doutoramento.

PELLERIN, J. et al. Cartografia Geológica e Geomorfólogica, bases para uma cartografia de riscos: exemplo no sul do Estado de Santa Catarina. Florianópolis: $3^{\circ}$ Simpósio Brasileiro de Cartografia Geotécnica, Florianópolis: UFSC. 1998.

PELLERIN, J; DUARTE, G. M; SCHEIBE, L. F; MENDONÇA, M; BUSS, M. D; MONTEIRO, M. A. Timbé do Sul - Jacinto Machado: Avaliação preliminar da extensão da catástrofe de 23-24/12/1995. In: GEOSUL, nº 23, 1997. p. 71 - 86.

PELLERIN, J; GAMA, A. M. R. C; NASCIMENTO, E. E.D.J; VALDATI, J; PAISANI, J. C; PONTELLI, M. E. Zoneamento e Efeitos morfodinâmicos da Enxurrada do dia 23/12/1995 nas Bacias dos Rios Figueira e Pinheirinho - SC. In: Sociedade e Natureza, v. 8, no 15. Uberlândia: Universidade Federal de Uberlândia, Departamento de Geociências/EDUFU. 1996a. p. 196 - 200.

PELLERIN, J; PAISANI, J. C; PONTELLI, M. E; VALDATI, J. Esboço preliminar das áreas sujeitas à enxurradas (risco potencial) na bacia do Rio Rocinha - Timbé do Sul, SC. Trabalho apresentado no Seminário da disciplina "Análise da Qualidade Ambiental" (Curso de Mestrado em Geografia/UFSC). Timbé do Sul: 1996b.

\section{NOTAS DE AUTOR}

\section{CONTRIBUIÇÃO DE AUTORIA}

Jairo Valdati - Concepção. Coleta de dados, Análise de dados, Elaboração do manuscrito, revisão e aprovação da versão final do trabalho.

Daner Rosskamp Ferreira - Concepção. Coleta de dados, Análise de dados, Elaboração do manuscrito, revisão e aprovação da versão final do trabalho.

Maria Carolina Villaça Gomes - Participação ativa da discussão dos resultados; Revisão e aprovação da versão final do trabalho.

\section{FINANCIAMENTO}

Não se aplica.

\section{CONSENTIMENTO DE USO DE IMAGEM}

Não se aplica.

\section{APROVAÇÃO DE COMITÊ DE ÉTICA EM PESQUISA \\ Não se aplica.}

\section{CONFLITO DE INTERESSES}

Não se aplica.

\section{LICENÇA DE USO}

Este artigo está licenciado sob a Licença Creative Commons CC-BY. Com essa licença você pode compartilhar, adaptar, criar para qualquer fim, desde que atribua a autoria da obra.

\section{HISTÓRICO}

Recebido em: 04-09-2019

Aprovado em: 11-09-2020 